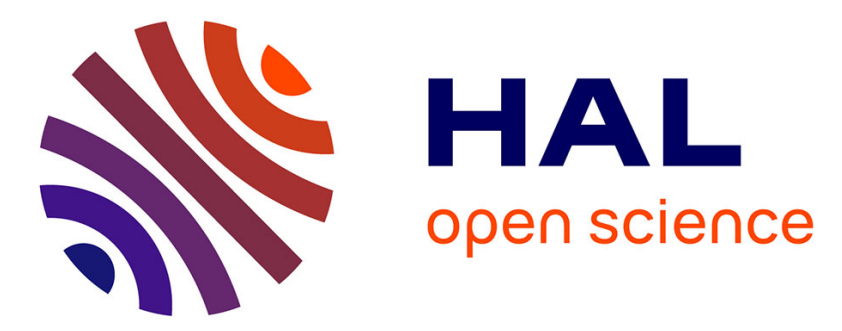

\title{
Theoretical and experimental study of the adsorption of neutral glycine on silica from the gas phase
}

\author{
Claire Lomenech, Gregoire Bery, Dominique Costa, Lorenzo Stievano,
} Jean-François Lambert

\section{To cite this version:}

Claire Lomenech, Gregoire Bery, Dominique Costa, Lorenzo Stievano, Jean-François Lambert. Theoretical and experimental study of the adsorption of neutral glycine on silica from the gas phase. ChemPhysChem, 2005, 6, pp.1061-1070. hal-00128574

\section{HAL Id: hal-00128574 \\ https://hal.science/hal-00128574}

Submitted on 1 Feb 2007

HAL is a multi-disciplinary open access archive for the deposit and dissemination of scientific research documents, whether they are published or not. The documents may come from teaching and research institutions in France or abroad, or from public or private research centers.
L'archive ouverte pluridisciplinaire HAL, est destinée au dépôt et à la diffusion de documents scientifiques de niveau recherche, publiés ou non, émanant des établissements d'enseignement et de recherche français ou étrangers, des laboratoires publics ou privés. 


\title{
Adsorption and Thermal Condensation Mechanisms of
} Amino Acids on Oxide Supports : 2/. Theoretical and experimental study of the adsorption of neutral glycine on silica from the gas phase

\author{
C. Lomenech, G. Bery, D. Costa*, L. Stievano and J. F. Lambert
}

Laboratoire de Réactivité de Surface, UMR CNRS 7609, Université Pierre et Marie Curie, case courrier 178, 4 place Jussieu, 75252 Paris Cedex 05, France

* to whom correspondance should be addressed : costa@ccr.jussieu.fr 
ABSTRACT The adsorption of neutral glycine onto amorphous silica was investigated both theoretically and experimentally. DFT calculations were performed at the BLYP-631++G** level using a cluster approach. Several possible configurations involving the formation of H-bonds between glycine and one, two or three silanols, $(\mathrm{SiOH})$ were considered. The most favorable bonding of glycine with one silanol (45 kJ/mol) occurs through the $\mathrm{COOH}$ moiety, forming a cycle in which the $\mathrm{CO}$ group is $\mathrm{H}$-bond acceptor whereas the acidic $\mathrm{OH}$ group is $\mathrm{H}$-bond donor. With two or three silanols, additional H-bonds are formed between the amine moiety and the silanols, leading to an increased adsorption energy (70 and $80 \mathrm{~kJ} / \mathrm{mol}$ for two and three silanols respectively). Calculated $v_{\mathrm{CO}}$, $\delta_{\mathrm{HNH}}$ and $\delta_{\mathrm{HCH}}$ are sensitive to the adsorption mode. A bathochromic shift of vCO as compared to vCO of free glycine (calculated in the $1755-1790 \mathrm{~cm}^{-1}$ range) is found for glycine in interaction with silanol(s). The more H-bonds of $\mathrm{COOH}$ with silanol groups, the higher the bathochromic shift. For $\delta \mathrm{HNH}$, no shift is found for glycine adsorbed on one and two silanols (where the amine is either not bound or $\mathrm{H}$ bond donor), whereas a bathochromic shift is calculated with three silanols when the amine moiety is H-bond acceptor. Experimental FTIR spectra performed at RT for glycine adsorbed at $160^{\circ} \mathrm{C}$ on Aerosil amorphous silica exhibit bands at 1371, 1423, 1630 and $1699 \mathrm{~cm}^{-1}$. The experimental/calculated frequencies have their best correspondance for glycine adsorbed on two silanols. It is important to note that the forms giving the best correspondence to experimental frequencies are the most stable ones.

\section{TITLE RUNNING HEAD : Adsorption of Glycine on Silica}

KEYWORDS : Glycine, silica, hydroxyl, silanol, adsorption, infrared spectroscopy, DFT, modeling, hydrogen bonding 
INTRODUCTION The adsorption mechanism of amino acids and of biological molecules on the surface of solid materials (metals and oxides) has attracted a lot of attention ${ }^{1,2,3}$, since it is of great importance both from the fundamental and the applied point of view. An increasing number of applications regarding solid-phase peptides synthesis, development of organic mass spectrometry, medical implants and biomedical sensors, are based on such systems ${ }^{4}$. Moreover, the adsorption of simple aminoacids is the first step of the mechanism of peptide bond formation and chain elongation on solid oxides, including silica, alumina and clay, which may have played an important role in the process of prebiotic chemical evolution ${ }^{5}$.

Our research has long been focused on the molecular description of specific adsorption sites on amorphous silica when the adsorbed species is a transition metal ion or a transition metal complex. In particular, an approach combining molecular modeling with spectroscopic data has been successfully applied to the study of transition metal/silica systems ${ }^{6,7}$. More recently, we have started to investigate the adsorption of small biological molecules such as amino acids on the same support. ${ }^{8}$

Here, we have attempted as a first step to model the adsorption of glycine on silica in conditions of low water activity. For meaningful comparison, experimental results have been obtained by adsorbing glycine from the gas phase. These results will be compared, in a forthcoming paper, with those obtained at the solution/solid interface, where molecular simulations are carried out including water molecules to characterize the effects of solvation on the adsorption mechanism.

There are few available data in the literature on amino acids/silica systems in anhydrous conditions. A notable exception is the work of Basiuk et al. ${ }^{9}$ who have adsorbed several amino acids on silica from the gas phase, but they reported that only a limited amount of glycine was adsorbed in their conditions.

The surface of amorphous silica is covered with silanol groups $\left(5 \text { per } \mathrm{nm}^{2}\right)^{10}$ which can easily form hydrogen bonds with molecules. On the other side, glycine has two reactive groups able to form $\mathrm{H}$ bonds, the $\mathrm{COOH}$ and the $\mathrm{NH}_{2}$ groups. In the present study, we investigate the possible ways of bonding of gaseous glycine with hydroxylated silica. For all considered configurations, the harmonic frequencies of normal vibrational modes have been calculated. We have focused on the vibrations of the 
amine and carboxyl groups that are susceptible of being affected by bonding to the silanols. The results are then compared with experimental data.

\section{METHODOLOGY AND EXPERIMENTAL}

Glycine conformers modeling DFT and especially B3LYP studies have been successfully used for modeling intramolecular hydrogen bonds formed in several conformers of glycine ${ }^{11}$ and intra- and intermolecular bonds in zwitterionic hydrated glycine. ${ }^{9}$ For this reason, we have used the B3LYP functional in the present study, with a $6-31++G^{* *}$ basis set. Some complementary results using either the 6-311++G** basis or MP2 level of theory are also reported. Calculations have been performed with the Gaussian 98 package. $^{12}$ Full geometry optimizations were performed, otherwise precised in note, followed by the calculation of the vibrational frequency. This allowed us to determine whether the optimized geometry corresponds to a local minimum or to a transition state. Here, only results corresponding to local minima (absence of any imaginary frequency) are reported.

It has been established that gaseous glycine principally exists as three conformers, ${ }^{12,13}$ which have therefore been considered in the present study. Geometries, energies and harmonic frequencies of all three conformers obtained by optimization at the B3LYP, 6-31++G** level were calculated recently ${ }^{14}$ and agree well with previously published results ${ }^{12}$. In addition, the authors of ref 15 Or is it 14 ? present results of glycine bound to 1, 2, and up to four water molecules, where vibrational frequencies fit pretty well the experimental ones obtained in Ar matrix. The authors used anharmonic/harmonic factors of 0.98 for out of plane bending, 0.95 for $\mathrm{X}-\mathrm{H}$ stretching and 0.975 for other modes. The same values are used here.

Silica surface modeling The surface of silica has been widely studied by theoreticians, both with a cluster and a periodic approach. The choice of the method is still a matter of debate. On the one hand, it has been claimed that cluster calculations, which cannot take into account the long range interaction terms and the constraints imposed by the surroundings, are not suitable to describe $\mathrm{H}$ bond interactions 
between silanols, ${ }^{15}$ but on the other hand, the quartz, ${ }^{16,16}$ edingtonite ${ }^{17}$ or cristobalite ${ }^{17}$ surfaces usually considered for periodic calculations do not reproduce the ratio of the different types of silanols present on the real surface of silica, nor the distribution of the different sizes of rings on the surface. Moreover, the cluster approach with the B3LYP functional has been shown to be well-suited for the study of Hinteraction of small molecules $\left(\mathrm{H}_{2}, \mathrm{CO}, \mathrm{H}_{2} \mathrm{O}, \mathrm{NH}_{3}, \mathrm{MeOH}\right)$ with the silanols. ${ }^{18}, 19$

On the real silica surface, isolated, geminal, vicinal and adjacent silanols may be found. Isolated silanols were modeled here using a simple $\mathrm{H}_{3} \mathrm{SiOH}$ cluster. Geminal silanols were modeled using a $\mathrm{Si}(\mathrm{OH})_{4}$ cluster. In this cluster, free optimization led to non-interacting $\mathrm{OH}$ groups. Vicinal silanols were modeled with the $\mathrm{H}_{2} \mathrm{Si}(\mathrm{OH}) \mathrm{OSi}(\mathrm{OH}) \mathrm{H}_{2}$ cluster. The Si---Si distance is around $3 \AA$. The optimized geometries are found in the supplementary materials.

Adjacent silanols (silanols in which the two OH-bearing Si are separated by an O-Si-O linkage) were not explicitly modeled here. Recent ab initio molecular dynamics calculations indicate that the Si---Si distances of two Si bearing adjacent silanols are between 4 and $6 \AA{ }^{20}$

As for glycine, the harmonic frequencies calculated after geometry optimization can be compared with experimental data: if the anharmonic/harmonic ratio is taken as 0.961 (very close to the value of 0.956 calculated by Civalleri et al) ${ }^{21}$ on the basis of the frequency of isolated silanols (3747-3750 $\mathrm{cm}^{-1}$, taken as the average value of $3748.5 \mathrm{~cm}^{-1}$ ), the non-interacting geminal silanols are predicted to vibrate in the 3737-3740 $\mathrm{cm}^{-1}$ range, and the non-interacting vicinal silanols at $3736 \mathrm{~cm}^{-1}$ (experimental data: 3735-3742 $\mathrm{cm}^{-1}$ ); while the interacting vicinal and adjacent silanols vibrate at values inferior to 3735 $\mathrm{cm}^{-1}$, as expected for H-bonded silanols. Such satisfactory results were already obtained in the past using small clusters and are encouraging for studying the reactivity of silanols. ${ }^{22-23}$ Periodic calculations have confirmed the accuracy of these small cluster approaches for calculating $\mathrm{OH}$ stretch frequencies of isolated silanols ${ }^{24}$. 
Modeling of glycine/silica adsorbed complexes The interaction of glycine with one, two and three free silanols has been studied. The positions of silanols were not constrained, but the Si---Si distances after optimization were used as a criterion to evaluate the chemical plausibility of the optimized configuration as an adsorption site. An important number of starting configurations (approximately 70) have been considered. They converged to 30 final geometries. We are therefore rather confident that we have checked the most probable configurations for the interaction of glycine with one, two or three silanols. The most illustrative results are given here. In the last step, special configurations were considered, such as the interaction of glycine with geminal and vicinal silanols.

\section{Energies of interaction:}

The foremost usefulness of our calculations is to evaluate the energies of interaction between glycine and the silica surface, corresponding to the various configurations studied. The net energy of adsorption, $\Delta_{\mathrm{ads}} \mathrm{E}$, for a given configuration is defined here as the total energy of this configuration (in $\mathrm{kJ} . \mathrm{mol}^{-1}$ ), minus the sum of the total energy of glycine conformer I (Gly1, the most stable), and the total energy(ies) of the optimized silanol cluster(s) on which adsorption is taking place. Thus, it corresponds to the energy released by a process that can be assimilated to an adsorption from the gas phase. The BSSE error was calculated to be around $1 \mathrm{~kJ} \mathrm{~mol}^{-1}, 2 \mathrm{~kJ} \cdot \mathrm{mol}^{-1}$ and $4 \mathrm{~kJ} \cdot \mathrm{mol}^{-1}$ for glycine interacting with 1, 2 and $3 \mathrm{SiOH}$ respectively. It has been shown that the full counterpoise method is not necessary for evaluate the BSSE for glycine-water bonded systems. ${ }^{25}$

It is also useful to compare different configurations of glycine adsorbed on the same surface site. We evaluate the relative energies of these binding isomers $(\Delta \mathrm{E})_{\text {isom, }}$, by subtracting from the total energy of the configuration under consideration the total energy of the most stable configuration obtained on the same silanols cluster. Thus, positive values of $(\Delta \mathrm{E})_{\text {isom }}$ indicate relative destabilizations.

The models discussed here involve the formation of hydrogen bonds. It has been proposed in ref.6. to determine the formation of an H-bond on the basis of a distance criterion, i.e. H-bonding will be 
assumed when the $\mathrm{H}^{\cdots} \cdots$ acceptor atom distance is shorter than the sum of the van de Waals radii $(0.27 \mathrm{~nm}$ for an H-bond to an oxygen acceptor). We will adhere to this definition in the discussion.

Experimental preparation of glycine/silica samples and IR spectroscopy In order to compare theoretical predictions with experimental data, glycine was deposited on a sample of amorphous silica using a CVD-type procedure. Deposition from the gas phase is the simplest way to insure that glycine contacts the surface as neutral molecules rather than as zwitterions, which constitute the stable form of glycine in conditions of high water activity.

In a typical experiment, the appropriate amount of $\alpha$-glycine (Aldrich) is placed on the bottom of a glass U-tube reactor fitted with a quartz frit. About $1.5 \mathrm{~g}$ of silica (Aerosil 380, Degussa), previously dehydrated at $100^{\circ} \mathrm{C}$ overnight, are placed on the frit and the reactor is homogeneously heated at $160^{\circ} \mathrm{C}$ for 15 hours in argon flow $(100 \mathrm{ml} / \mathrm{min})$, then cooled down to room temperature. The same thermal treatment was applied to a blank silica sample without glycine in the reservoir.

The samples were pressed into self-supported pellets immediately after cooling. Preparation of the pellets implied exposure to air for 2 to 3 minutes, following which FT-IR spectra were recorded in the transmission mode under flowing nitrogen at room temperature on a Vector 22 Infrared Spectrometer (Bruker).

\section{RESULTS}

\section{I/ Interaction of neutral glycine with an isolated silanol group, $\mathrm{H}_{3} \mathrm{SiOH}$}

Five different models were considered in which the binding of the neutral glycine to the silanol group proceeds via:

- the two oxygen atoms of the carboxyl function (configuration I-a),

- the oxygen of the carbonyl group, and the amine function (configuration I-b), the amine being proton donor and the oxygen proton acceptor 
- the $\mathrm{OH}$ group of the carboxyl group, and the amine function (configuration I-d), the amine being proton acceptor and the $\mathrm{OH}$ proton donor

- the amine function, either as a proton-acceptor (configuration I-c) or as a proton-donor (configuration I-e)

The optimized geometries are shown in Figure 1 together with the total energies of the clusters. In each case, the glycine molecule takes part in two hydrogen bonds; in some cases, both bonds are between the glycine molecule and the silanol group, in the other cases one bond is between glycine and silanol, and the second is an intramolecular bond in glycine. Thus, the differences in energy between the various adsorbed forms depend on differences in the $\mathrm{H}$ bonds strengths rather than in their numbers.

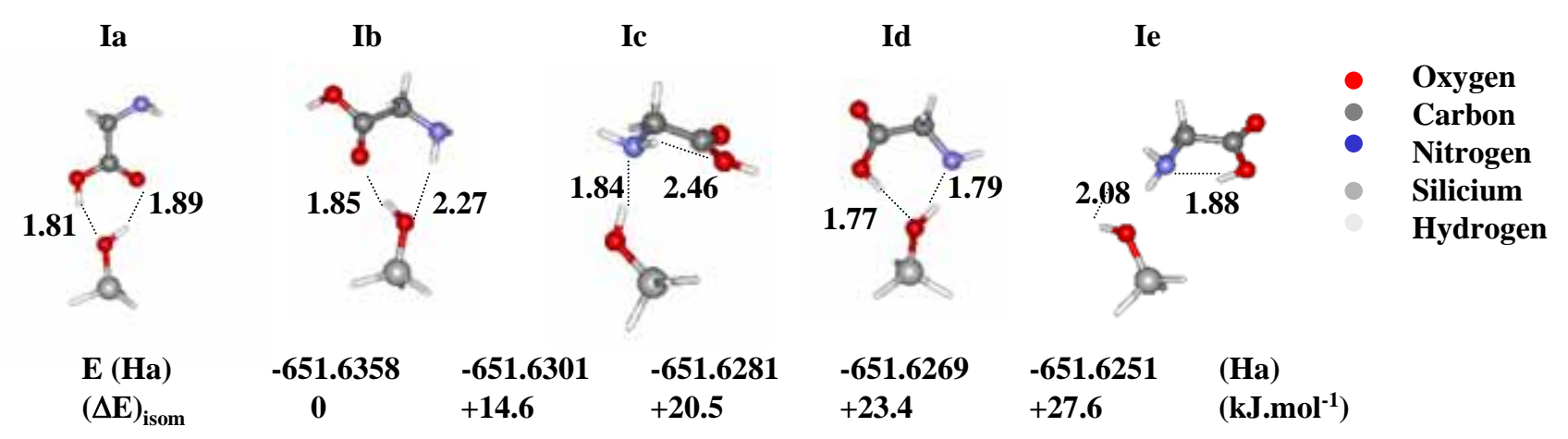

Figure 1 : Optimized geometries, total energies and relative energies of the different isomers obtained for the interaction of glycine with one silanol. The $\mathrm{H}$ bond distances are reported in $\AA$.

The most stable configuration (I-a) is obtained when the carboxylic acid group forms two hydrogen bonds with the silanol, with the carbonyl oxygen as an H-bond acceptor, and the acidic -OH group as an H-bond donor.

In configuration I-b, about $14 \mathrm{~kJ} / \mathrm{mol}$ less stable than I-a, the carboxyl group is still an $\mathrm{H}$-bond acceptor, but the amine is the H-bond donor. Configurations I-c to I-e are $20-28 \mathrm{~kJ} / \mathrm{mol}$ less stable than configuration I-a. In configuration I-c, the amine group is H-bond acceptor with a short ( $\mathrm{SiOH} \cdots \mathrm{N})$ bond 
(1.84 $\AA$ ), close to the lengths of the $\left(\mathrm{SiOH}^{\cdots} \mathrm{O}\right)$ bonds formed in the previous two configurations. In configuration 1d, two short $\mathrm{H}$-bonds $\left(\mathrm{SiOH}^{\cdots} \mathrm{N}\right.$ and $\left.\mathrm{COOH}^{\cdots}(\mathrm{OH}) \mathrm{Si}\right)$ are present. In configuration I-e, the amine group is H-bond donor with a slightly longer bond (2.06 $\AA$ ). As expected from the basic character of the amine group of glycine, ${ }^{15}$ configuration I-c is more stable than configuration I-e (by 7.1 $\mathrm{kJ} / \mathrm{mol})$.

Configurations $1 \mathrm{~b}$ and $1 \mathrm{~d}$ exhibit an interesting feature that will recurrently be found in the following paragraphs: the intramolecular H-bonds of glycine have been broken and replaced by an "indirect $\mathrm{H}$ bond” implying the insertion of the silanol between the amine and the carboxylic acid moieties. In other words, the silanol is "solvating" the glycine. This situation will be hereafter referred to as carboxylamine silica bridging: "CASB" configuration. Note that the " $\mathrm{H}$ donor $=\mathrm{NH}_{2}, \mathrm{H}$ acceptor $=$ OC" configuration is $8 \mathrm{~kJ} / \mathrm{mol}$ more stable than " $\mathrm{H}$ donor $=\mathrm{COOH}, \mathrm{H}$ acceptor $=\mathrm{NH}_{2}$ ". Thus, the energetic loss due to the unfavorable $\mathrm{H}$ bond-donating properties of the amine (about $7 \mathrm{~kJ} / \mathrm{mol}$ ) is overcompensated by the favorable $\mathrm{H}$ bond-accepting properties of the carbonyl oxygen.

These first results suggest that neutral glycine preferentially interacts with surface silanols via its carboxyl group.

\section{II/ Interaction of neutral glycine with several isolated silanol groups}

As already mentioned, the surface of silica does not only present isolated silanols, but also groups of silanols in close proximity. It is therefore expected that a molecule of adsorbed glycine may interact with more than one silanol at the same time, and the effect of additional silanols has to be considered to obtain a realistic picture.

In a first step, two or three silanols were placed at a large enough distance to prevent any interaction with each other. No constraint, however, was imposed on their position and they were left free to move in space during the optimization. Although silanols on a silica surface are not expected to have such a freedom of motion, this procedure should allow us to spot the "best possible" silanols configurations, 
i.e. those that allow the most stable interaction with a glycine. If such configurations exist on the silica surface, they might constitute sites for specific adsorption.

Three models were selected to evaluate which functional group(s) of the glycine molecule preferentially interact with two free silanol groups. They respectively involve bonding via:

- the carboxylic acid group alone (configuration II-a). The initial bonding in this configuration is similar to configuration I-a.

- both functions involved in a CASB configuration (II-b). The results of §II indicated that, if glycine is bonded to a single silanol via both its terminal groups, the "CO-acceptor, $\mathrm{NH}_{2}$-donor" configuration is more stable that the "N-acceptor, OH-donor" configuration (compare configurations I-b and I-d). Therefore, only the first type of configuration was considered as a starting point for the calculations of the CASB on two silanol groups. Thus, the initial configuration in II-b is similar to I-b.

- the amine group alone (initial configuration II-c) : this initial configuration is similar to I-c.

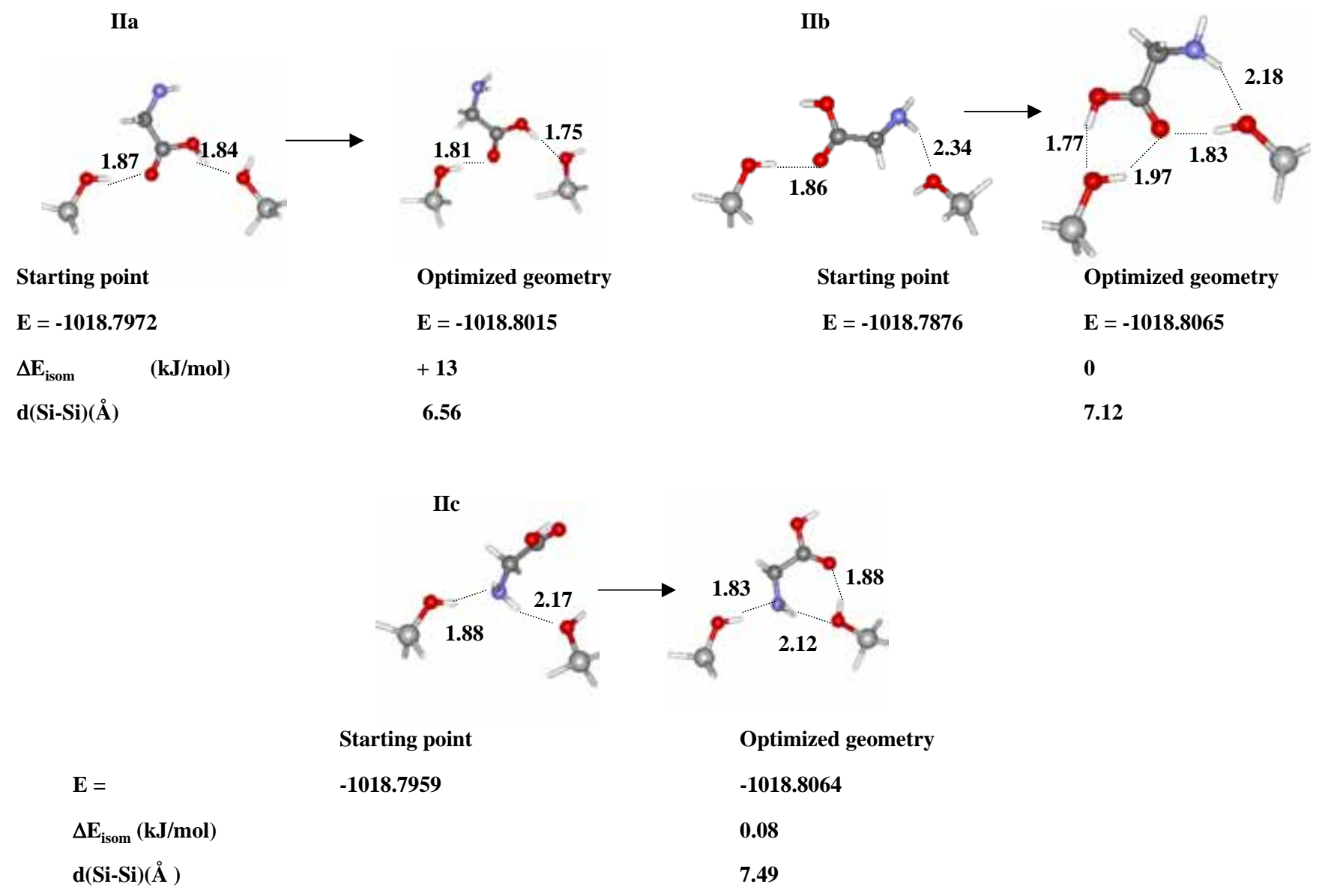


Figure 2 : Initial (left), final (right) geometries, total energies (Ha), relative energies of the different optimized configurations, and Si---Si distances in the optimized geometries of glycine in interaction with two free silanol groups

The geometries selected as starting points for the optimization are presented in Figure 2, together with the resulting final configurations. As a first remark, even though the silanol groups moved during optimization, they remained isolated from each other (too distant to establish H-bonding interactions).

When glycine is bonded via the two oxygen atoms of the $\mathrm{COOH}$ group, the carboxyl $\mathrm{OH}$ being proton-donor and the carbonyl proton-acceptor (configuration II-a), no drastic change happens during the geometry optimization.

In contrast, for configurations II-b and II-c, the structures undergo remarkable changes during geometry optimization, with the formation of supplementary H-bonds, and result in a geometry where both the carboxyl and the amine functions are implied (even though the carboxyl group was not bonded to silica at the starting point). Indeed, starting from a bonding of the amine group alone with the silanol moieties, configuration II-c stabilizes with the formation of a bond between the carbonyl oxygen and one silanol group, by rotation of the $\mathrm{CH}_{2}-\mathrm{COOH} \sigma$-bond.

Configuration II-b involved at the beginning of the calculation only one bond of each of the carboxyl and amine functions with the two silanol groups. It stabilizes with the formation of two supplementary H-bonds: the H-acceptor oxygen gets involved in a bridge between the two silanol groups, while the $\mathrm{OH}$ group becomes H-donor in a bonding with one silanol group.

Configurations II-b and II-c are of similar stability (energy difference: 0.08 kJ.mol ${ }^{-1}$ ). A complementary calculation was performed at the B3LYP/6-311++G** level. After total optimization, the geometries were found very near those found at the $6-31++G^{* *}$ level. This calculation confirmed that configuration II-b is slightly more favorable; a somewhat higher separation between b and c was obtained $(2.6 \mathrm{~kJ} / \mathrm{mol})$.

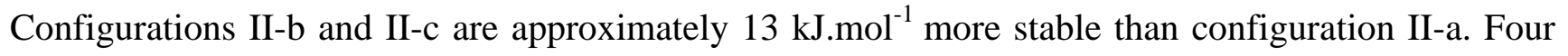
and three H-bonds between glycine and silanols are present in configurations II-b and II-c respectively, 
whereas only two H-bonds are formed in configuration II-a. It should be noticed that the two more stable final states have some structural similarity with the more stable configurations observed for interaction with a single silanol (I-a and I-b): in configuration II-b, the carboxyl group is bound to one of the silanols in the same way as in configuration I-a; in configuration II-c, the amine and carboxyl functions are linked to one of the silanols group in the same way as in configuration I-b.

A similar trend is observed when considering the interaction of glycine with three isolated silanols. In this case, four hydrogen bonds are present. Figure 3 shows the three most stable configurations achieved after optimization. In all three cases, both oxygen atoms of the carboxylic acid groups are involved in the bonding with the silanol groups, while an additional "CASB" bonding forms. In contrast with previous configurations (binding with one or two silanols), here the CASB involving the NH of the amine as an H-bond acceptor is more stable than the CASB with the $\mathrm{NH}$ of the amine as an $\mathrm{H}$-bond donor.

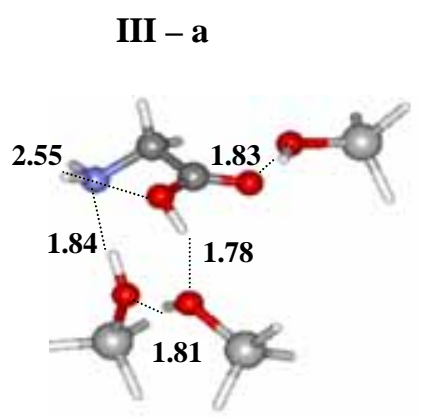

E (Ha) $\Delta \mathbf{E}_{\text {isom }}(\mathrm{kJ} / \mathrm{mol}) \quad 0$ $\mathrm{d}(\mathrm{Si}-\mathrm{Si})(\AA) \quad 4.93,7.19,7.43$

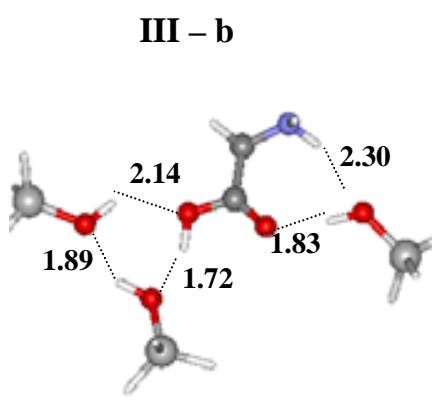

$-1385.9793$

9.7

$5.62,7.45,10.56$

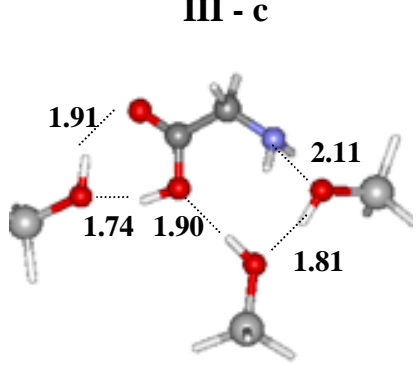

$-1385.9788$

11

5.30, 6.37, 9.08

Figure 3: Optimized geometries obtained for the interaction of glycine with three free silanol groups In all cases, the structure evolved during the optimization towards a configuration where two silanols form H-bonds between each other and with glycine, and one silanol bonded only to glycine. The closest distances between the bonded silanols (around 5-6 A) correspond to adjacent silanols. Such silanols can exist in the 5-rings or 6-rings, which are the most common on the silica surface. ${ }^{26}$ The longer distances (7-10 $\AA$ ) correspond to larger cycles, or possibly to different arrangements of silanols in the same 
cycles. For the most stable structure, (III-a), an optimisation of geometry was conducted taking into account an entire cycle (a 7T-ring), without change of the geometry of the adsorbed glycine on the silanols.

In order to verify the accuracy of the energies of interaction calculated at the B3LYP level, calculations at the MP2 level (for the geometries optimized at the B3LYP level) were performed for the most stable configurations. The glycine adsorption energies corresponding to the most stable configurations obtained for one, two and three silanols are: $-45.1,-68.7$ and $-83.6 \mathrm{~kJ} / \mathrm{mol}$ at the B3LYP level and $-31,-54$ and -111 at the MP2 level respectively. The absolute value of the adsorption energy increases by 23-24 kJ/mol (both at the B3LYP and MP2 level) when going from one to two silanols. A further stabilisation is observed when going from two to three silanols, by $14.9 \mathrm{~kJ} / \mathrm{mol}$ at the B3LYP level and as much as $57 \mathrm{~kJ} / \mathrm{mol}$ at the MP2 level. This may be attributed to the increase of the number of hydrogen bonds formed between the glycine and the surface (from two to three, then to four): indeed, at least the first of these values lies in the typical range for the formation of a hydrogen bond (calculated value at the B3LYP level for one $\mathrm{H}$ bond between two $\mathrm{H}_{2} \mathrm{O}: 25 \mathrm{~kJ} / \mathrm{mol}$ ).

\section{Adding geometric constraints induced by the surface : interaction of glycine with geminal}

\section{and vicinal silanol groups}

In the previous sections, the interaction of glycine with silica was investigated using one to three free $\mathrm{H}_{3} \mathrm{SiOH}$ clusters to model the silica surface. These clusters would correspond, in practice, either to isolated silanol groups, or to "adjacent” silanols, as noted in section II (see the argument about the optimized Si-Si distances). Two other types of silanol groups are known to be present at the surface of silica: geminal and vicinal sites, which correspond to geometrically more constrained structures that cannot be realistically modeled by several free silanol clusters.

The influence of the geometrical constraints of the surface sites on the stability of the glycine/silica surface complex has been evaluated systematically for one particular configuration, namely adsorption via the carboxyl group (i.e., the more stable configuration obtained on one free silanol group). We have tried to reproduce this configuration on the following series corresponding to 
the different types of silanol groups: one free (isolated) silanol (configuration I-a, Figure. 1 and Figure. 4), two geminal silanols (configuration II-G, Figure. 4), two vicinal silanols (configuration II-V, Figure. 4), and two adjacent silanols (configuration II-a, Figure. 2 and Figure. 4). The optimized geometries are presented in Figure 4.

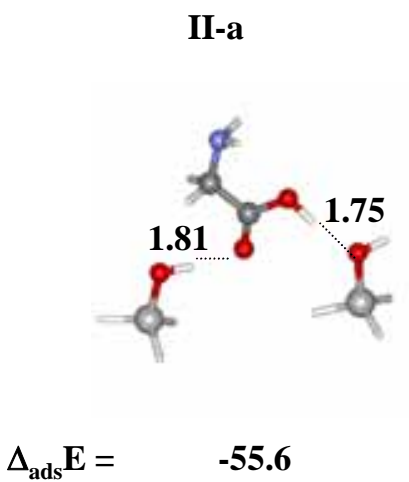

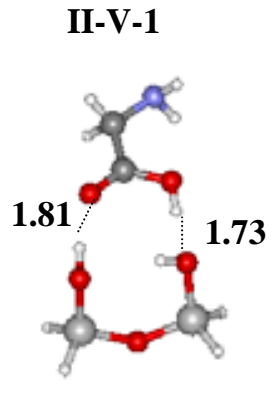

$-53.2$

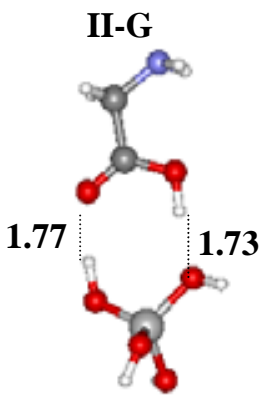

$-50.9$

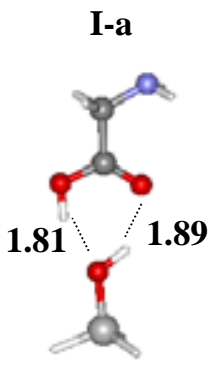

45.1

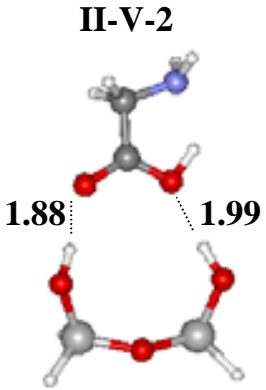

$-39.6$

Figure 4: Optimized geometries for glycine adsorbed on silica via the carboxyl group, on a series of clusters representing the different types of sites on the surface of silica, and corresponding glycine adsorption energies $\left(\mathrm{kJ} . \mathrm{mol}^{-1}\right)$.

In all five geometries, the optimized lengths of the two H-bond established between the carboxyl group and the silanols are short: between 1.75 and $1.89 \AA$, in the same range as those found for the geometrically unconstrained cases.

The adsorption energies of the different geometrically constrained configurations are summarized in Figure 4 and table 1. 
Table 1: Summary of the total energies and adsorption energies for the configurations considered in this study.

\begin{tabular}{|c|c|c|c|c|c|c|}
\hline $\begin{array}{l}\text { Number of } \\
\mathrm{SiOH} \\
\text { groups }\end{array}$ & $\begin{array}{l}\text { Configura } \\
\text { tion } \mathrm{N}^{\circ}\end{array}$ & \begin{tabular}{|ll} 
Binding & mode \\
to & $\mathrm{SiOH}$ \\
group(s) & \\
\end{tabular} & $\begin{array}{l}\text { Binding mode of } \\
\text { the amine group }\end{array}$ & $\begin{array}{l}\text { Total } \\
\text { energy(Ha) }\end{array}$ & $\begin{array}{l}\Delta_{\text {Ads }} \mathrm{E} \\
(\mathrm{kJ} / \mathrm{mol}) \\
\text { B3L YP }\end{array}$ & $\begin{array}{l}\Delta_{\text {Ads }} \mathrm{E} \\
(\mathrm{kJ} / \mathrm{mol}) \\
\mathrm{MP} 2\end{array}$ \\
\hline \multirow{5}{*}{ one } & I-a & $\mathrm{COOH}$ & (not bound) & -651.6358 & -45.1 & -31 \\
\hline & I-b & CASB & H donor & -651.6301 & -30.2 & \\
\hline & $\mathrm{I}-\mathrm{C}$ & amine & H acceptor & -651.6281 & -24.9 & \\
\hline & I-d & CASB & H acceptor & -651.6269 & -21.8 & \\
\hline & I-e & amine & H donor & -651.6251 & -17.0 & \\
\hline \multirow[b]{3}{*}{ two } & II-a & $\mathrm{COOH}$ & (not bound) & -1018.8015 & -55.6 & \\
\hline & II-b & $\mathrm{CASB}+\mathrm{COOH}$ & H donor & -1018.8065 & -68.7 & -54 \\
\hline & II-C & CASB + Amine & $\begin{array}{l}\text { H donor } \\
\text { H acceptor }\end{array}$ & -1018.8064 & -68.5 & \\
\hline 2, geminal & II-G & $\mathrm{COOH}$ & (not bound) & -877.4960 & -50.9 & \\
\hline 2, vicinal & II-V-1 & $\mathrm{COOH}$ & (not bound) & -1092.9397 & -53.2 & \\
\hline 2, vicinal & II-V-2 & $\mathrm{COOH}$ & (not bound) & -1092.93452 & -39.6 & \\
\hline three & III-a & $\mathrm{CASB}+\mathrm{COOH}$ & H acceptor & -1385.9830 & -83.6 & -111 \\
\hline three & III-b & $\mathrm{CASB}+\mathrm{COOH}$ & H donor & -1385.9793 & -73.9 & \\
\hline three & III-C & $\mathrm{CASB}+\mathrm{COOH}$ & H donor & -1385.9788 & -72.6 & \\
\hline
\end{tabular}

Comparing the II-V-1 and II-V-2 configurations, it appears that the "H-donor H-acceptor" configuration is more stable than the "two H-acceptors” configuration.

For the most stable bonding mode ("H-donor H-acceptor"), the addition of a second silanol always results in the stabilisation of the $\mathrm{COOH}$-bonded glycine configuration (compare I-a on the one hand with II-G, II-V-1 and II-a on the other hand), even though glycine is involved in only two H-bonds. Among the configurations implying two silanols, the stablest is, as could be expected, the one in which the two surface groups are left completely free (II-a). With respect to the latter, the configuration with vicinal silanols is only slightly less favorable (by $+2.4 \mathrm{~kJ} \mathrm{~mol}^{-1}$ ), and that with geminal silanols yet a 


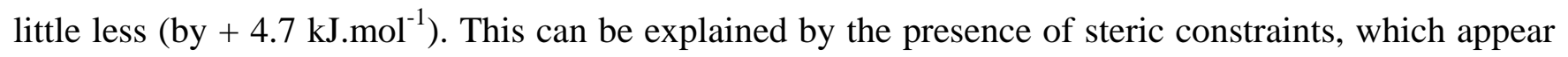
to be stronger on the geminal sites than on the vicinal sites, and that are, obviously, completely absent in the free-silanols case. We have also investigated the possibility of CASB binding to two vicinal silanols. The CASB configuration can be stabilized on vicinal silanols only at the cost of a substantial deformation of the Si-O-Si bond angle, which opens to $166.5^{\circ}$. As the mean Si-O-Si angle in silica is found to be $144^{\circ 27}$ and $153^{\circ 28}$, CASB-type adsorption of glycine does not seem to be likely on two vicinal silanols.

\section{Calculated frequencies of the CO stretching and HNH bending vibrations}

For glycine in interaction with hydroxylated silica, the $\mathrm{OH}$ stretching vibration of the carboxylic acid group will be difficult to observe experimentally since it will overlap with the $\mathrm{OH}$ stretch frequencies of the silica surface silanols (around $3650 \mathrm{~cm}^{-1}$ ) and of any residual water that may be present. Similarly, the $\mathrm{HNH}$ bending modes of the amine group may overlap with water bending modes (around $1600 \mathrm{~cm}^{-}$ ${ }^{1}$ ), unless deuteration techniques are used. Thus, the $\mathrm{OH}$ stretch frequencies of adsorbed glycine are not discussed here, and conversely particular attention will be paid in the present work to the CO stretch frequency. Table 2 reports the calculated CO stretching and HNH bending vibration frequencies of glycine interacting with one or several $\mathrm{SiOH}$ groups. 
Table 2 : Calculated wavenumbers for the different glycine binding modes with one, two and three silanols considered in the present study (bold : frequencies calculated for the most stable configurations with 1, 2 and 3 silanols)

\begin{tabular}{|c|c|c|c|c|c|c|}
\hline \multirow[t]{2}{*}{$\begin{array}{l}\text { Number } \\
\text { of } \mathrm{SiOH} \\
\text { groups }\end{array}$} & \multirow[t]{2}{*}{$\begin{array}{l}\text { Conf } \\
\text { and } \\
\text { fig }\end{array}$} & \multirow[t]{2}{*}{$\begin{array}{l}\text { Binding mode of } \\
\text { the } \mathrm{COOH} \text { group }\end{array}$} & \multirow{2}{*}{$\begin{array}{l}\text { Binding } \\
\text { mode of } \\
\text { the } \\
\text { amine } \\
\text { group }\end{array}$} & $\delta \mathrm{HCH}$ & $\delta \mathrm{HNH}$ & vCO \\
\hline & & & & Freq(Int) & Freq (int) & Freq (Int) \\
\hline \multirow[t]{3}{*}{ None } & Gly1 & & & $\begin{array}{l}1431 \\
1372\end{array}$ & 1649 & 1774 \\
\hline & Gly2 & & & $\begin{array}{l}1440 \\
1329\end{array}$ & 1633 & 1803 \\
\hline & Gly3 & & & $\begin{array}{l}1430 \\
1333\end{array}$ & 1647 & 1768 \\
\hline \multirow[t]{5}{*}{ One } & I-a & $\begin{array}{l}2 \text { : one } \mathrm{H} \text { donor } \\
\text { and one } \mathrm{H} \\
\text { acceptor }\end{array}$ & $\begin{array}{l}\text { (Not } \\
\text { bound) }\end{array}$ & $\begin{array}{l}1428 \\
(18) 1343(8)\end{array}$ & $1649(22)$ & $1723(315)$ \\
\hline & I-b & $1 \mathrm{H}$ acceptor & H donor & $\begin{array}{l}1426(21) \\
1379(20)\end{array}$ & $\begin{array}{l}1656 \\
30\end{array}$ & 1741 (435) \\
\hline & I-C & 0 & $\begin{array}{l}\mathrm{H} \\
\text { acceptor }\end{array}$ & $\begin{array}{l}1389(37) \\
1315(55)\end{array}$ & $1621(5)$ & $1784(331)$ \\
\hline & I-d & $\begin{array}{l}1 \\
\text { H donor }\end{array}$ & $\begin{array}{l}\mathrm{H} \\
\text { acceptor }\end{array}$ & $\begin{array}{l}1387(110) \\
1346(322)\end{array}$ & 1628 (39) & 1774 (333) \\
\hline & I-e & 0 & H donor & $\begin{array}{l}1402(368) \\
1331(5)\end{array}$ & $1644(26)$ & 1798 (397) \\
\hline \multirow[t]{2}{*}{ Two } & II-a & $\begin{array}{l}2 \\
\text { one } \mathrm{H} \text { donor and } \\
\text { one } \mathrm{H} \text { acceptor } \\
\text { bond }\end{array}$ & $\begin{array}{l}\text { (Not } \\
\text { bound) }\end{array}$ & $\begin{array}{l}1416(22) \\
1346(28)\end{array}$ & $1646(37)$ & $1710(441)$ \\
\hline & II-b & $\begin{array}{l}3 \\
\text { one } \mathrm{H} \text { donor and } \\
\text { two H acceptor } \\
\text { bonds }\end{array}$ & H donor & $\begin{array}{l}1450(24) \\
1392(5)\end{array}$ & 1649 (79) & 1701 (381) \\
\hline
\end{tabular}




\begin{tabular}{|c|c|c|c|c|c|c|}
\hline & II-C & $\begin{array}{l}1 \\
\text { H acceptor }\end{array}$ & \begin{tabular}{|l}
$\mathrm{H}$ donor \\
and \\
$\mathrm{H}$ \\
acceptor
\end{tabular} & $\begin{array}{l}1431(25) \\
1391(25)\end{array}$ & $1653(27)$ & $1744(414)$ \\
\hline & II-V-1 & $\begin{array}{l}2 \\
\text { one } \mathrm{H} \text { donor and } \\
\text { one } \mathrm{H} \text { acceptor } \\
\text { bond }\end{array}$ & $\begin{array}{l}\text { (Not } \\
\text { bound) }\end{array}$ & $\begin{array}{l}1409(27) \\
1339(32)\end{array}$ & 1647 (37) & 1708 (395) \\
\hline & II-V-2 & $\begin{array}{l}2 \\
\text { one } \mathrm{H} \text { donor and } \\
\text { one } \mathrm{H} \text { acceptor } \\
\text { bond }\end{array}$ & \begin{tabular}{|l} 
(Not \\
bound)
\end{tabular} & $\begin{array}{l}1403(466) \\
1325(20)\end{array}$ & $1632(42)$ & 1795 (464) \\
\hline & II-G & $\begin{array}{l}2 \\
\text { one } \mathrm{H} \text { donor and } \\
\text { one } \mathrm{H} \text { acceptor } \\
\text { bond }\end{array}$ & \begin{tabular}{|l} 
(Not \\
bound)
\end{tabular} & $\begin{array}{l}1408(19) \\
1332(29)\end{array}$ & $1646(37)$ & $1711(368)$ \\
\hline \multirow[t]{3}{*}{ Three } & III-a & $\begin{array}{ll}2 \text { : one } \mathrm{H} \text { donor } \\
\text { and one } \mathrm{H} \\
\text { acceptor bond }\end{array}$ & \begin{tabular}{|l}
$\mathrm{H}$ \\
acceptor
\end{tabular} & $\begin{array}{l}1408(58) \\
1376(19)\end{array}$ & $\begin{array}{l}1616 \\
(49)\end{array}$ & $\begin{array}{l}1738 \\
(427)\end{array}$ \\
\hline & III-b & $\begin{array}{l}2 \\
\text { one } \mathrm{H} \text { donor and } \\
\text { one } \mathrm{H} \text { acceptor } \\
\text { bond }\end{array}$ & H donor & $\begin{array}{l}1428(17) \\
1349(42)\end{array}$ & $\begin{array}{l}1654 \\
(29)\end{array}$ & $\begin{array}{l}1731 \\
(483)\end{array}$ \\
\hline & III-C & $\begin{array}{l}3 \\
\text { one } \mathrm{H} \text { donor and } \\
\text { two H acceptor } \\
\text { bonds }\end{array}$ & H donor & $\begin{array}{l}1422(2) \\
1357(2)\end{array}$ & $\begin{array}{l}1659 \\
(30)\end{array}$ & $\begin{array}{l}1731 \\
(321)\end{array}$ \\
\hline
\end{tabular}

For the CO stretching frequency, quite expectedly, the calculations indicate only small shifts with respect to free glycine when the molecule is adsorbed only via its amine group ( $v_{\mathrm{CO}}$ is around 1798$1784 \mathrm{~cm}^{-1}$, to be compared with $v_{\mathrm{CO}}$ for free glycine in the $1768-1803 \mathrm{~cm}^{-1}$ range). When an interaction is established between the silanol(s) and the $\mathrm{COOH}$ group, on the other hand, a strong bathochromic shift from the free glycine is calculated for this vibration mode, both when the carbonyl acts as an $\mathrm{H}$ - 
bond acceptor and when the acidic proton of the $\mathrm{COOH}$ acts as an H-bond donor. In fact, the band position is correlated with the number of $\mathrm{H}$ bonds between $\mathrm{COOH}$ and silica, as shown by Figure 5.

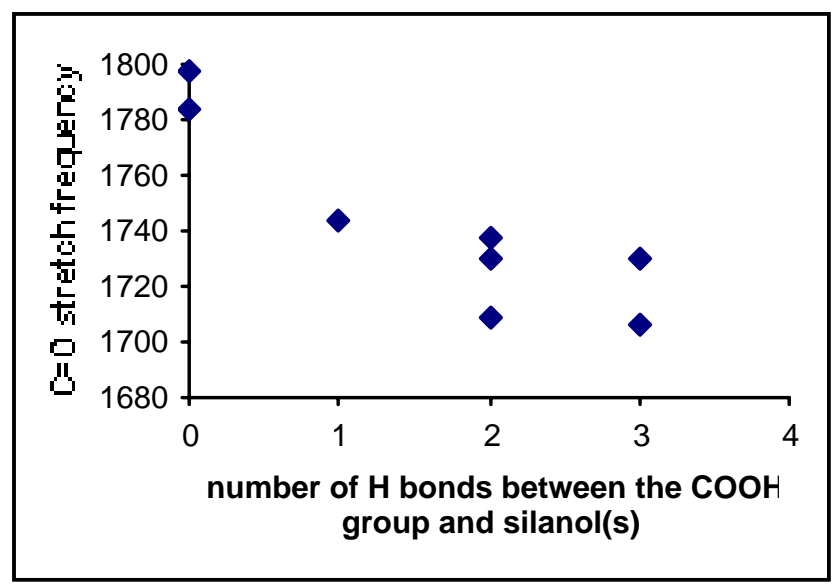

Figure 5 CO stretch frequency calculated for glycine in interaction with silanol(s), reported as a function of the number of $\mathrm{H}$ bonds of the $\mathrm{COOH}$ group with the silanols ; (when the number of $\mathrm{H}$ bonds is 0 , the glycine is in interaction only via the amine group with the silanol). $v_{\mathrm{CO}}$ for free glycine is calculated as 1774, 1803 and $1768 \mathrm{~cm}^{-1}$ for conformers Gly1, Gly2 and Gly3 respectively.

The HNH bending mode of course reacts in the opposite way to the $\mathrm{C}=\mathrm{O}$ stretching mode: only shifts smaller than $10 \mathrm{~cm}^{-1}$ are observed compared to free glycine when the amine group is not involved in the binding with $\mathrm{SiOH}$, or (less obviously) when it is proton donor. When the amine group is involved as a proton acceptor in the binding with silanols, a significant bathochromic shift $\left(20-30 \mathrm{~cm}^{-1}\right)$ of the HNH bending is calculated, although this effect is less pronounced than the one predicted for the CO stretch. Interestingly, the $\mathrm{H}$-acceptor binding mode of the amine is stabilized when the number of $\mathrm{SiOH}$ increases: while on a single $\mathrm{SiOH}$ it is $20 \mathrm{~kJ} \mathrm{~mol}^{-1}$ less stable than the preferred configuration, it becomes the ground configuration when glycine is bond to three silanols. A configuration with the amine exclusively $\mathrm{H}$ acceptor could not be stabilized with two silanols.

The $\mathrm{HCH}$ and $\mathrm{CCH}$ bending modes, calculated for free glycine (Gly1) at 1431 and $1373 \mathrm{~cm}^{-1}$ (and experimentally observed at 1429 and $\left.1373 \mathrm{~cm}^{-1}\right)^{12}$, are reported for the most stable configurations of glycine adsorbed on one, two and three silanols. The effects of adsorption on the $\mathrm{HCH}$ and the $\mathrm{CCH}$ vibration also seems to depend on the binding mode of glycine with the silanols. 


\section{Comparison with experimental data}

These theoretical predictions can now be compared to the experimental vibrational spectrum of glycine adsorbed on silica from the vapor phase.

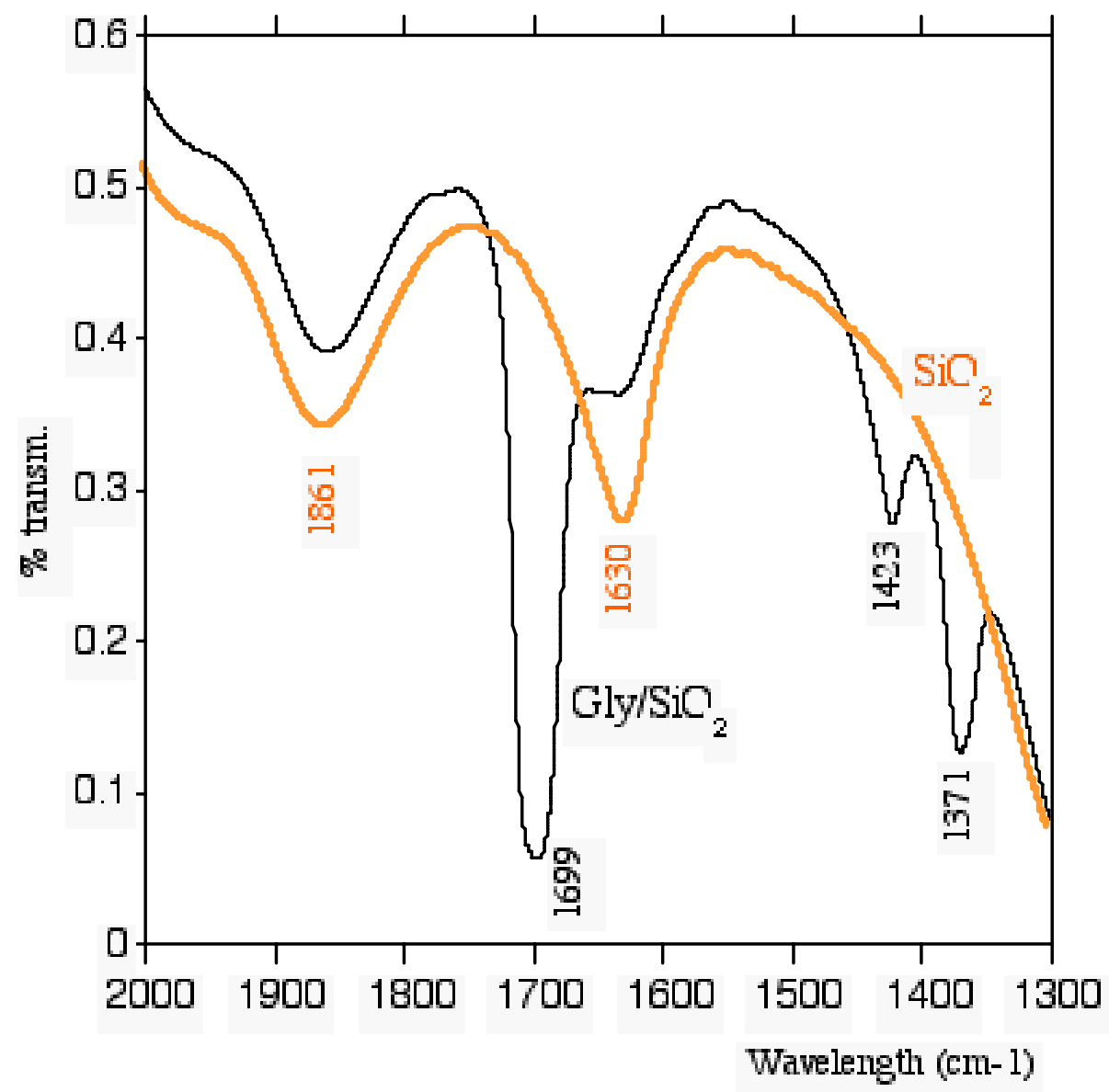

Figure 6: Transmission-mode FTIR spectrum in the $2000-1300 \mathrm{~cm}^{-1}$ region of silica powder, and glycine/silica prepared by CVD.

As seen in Figure 6, in addition to the bands at $1861 \mathrm{~cm}^{-1}$ (harmonic $v_{\text {asym }}$ SiOSi frequency) and $1630 \mathrm{~cm}^{-1}$ ( $\delta_{\mathrm{H}-\mathrm{O}-\mathrm{H}}$ of adsorbed water) observed for the naked silica support, glycine/silica exhibits three sharp new bands at 1699, 1423 and $1371 \mathrm{~cm}^{-1}$. The latter two are most probably due to the $\mathrm{HCH}$ and CCH bending modes of adsorbed glycine. The band at $1699 \mathrm{~cm}^{-1}$ can be assigned to a CO stretch of adsorbed molecular glycine, since it lies in the range of calculated frequencies for the various models, 
albeit at the low-energy end. As for the H-N-H bending mode, it probably lies around $1630 \mathrm{~cm}^{-1}$, but caution must be exercised because of possible interference with the $\delta_{\mathrm{H}-\mathrm{O}-\mathrm{H}}$ of water. Although the conditions we used for glycine deposition should suffice to remove most or all physisorbed water ${ }^{29,30}$, exposure to ambient air during pellet preparation may cause some water readsorption.

At any rate, it must be underlined that this spectrum cannot correspond to adsorbed zwitterions, $\left({ }^{+} \mathrm{H}_{3} \mathrm{~N}-\mathrm{CH}_{2}-\mathrm{COO}^{-}\right)$, whose behavior has been investigated in ref. 8. The ${ }^{+} \mathrm{H}_{3} \mathrm{~N}$ - moiety of the zwitterion has an asymmetric bending mode between 1480 and $1520 \mathrm{~cm}^{-1}$, which is missing here, and conversely the CO stretch observed in our samples is too energetic to be assigned to a carboxylate group. Thus, the short exposure of the samples to room humidity was insufficient to transform adsorbed glycine into the zwitterion - such a transformation, however, did indeed occur if the samples were more thoroughly rehydrated, by suspension into distilled water followed by drying at room humidity: this caused the $1699 \mathrm{~cm}^{-1}$ band to disappear completely, with the appearance of weak zwitterionic bands. The position of this band does not seem to correspond, either, to those observed by Basyuk et al. after vapor-phase deposition of several amino acids on silica, where bands at around $1760 \mathrm{~cm}^{-1}$ were assigned to Si-O-CO ester-type bonds (“surface esters”); however, no such data were reported for glycine on silica. ${ }^{31}$ Finally, the IR bands cannot be assigned to supported DKP, a possible product of glycine dimerisation; we have reported the spectrum of DKP supported on $\mathrm{SiO}_{2}$ in ref.8, and it differs in the position of $v_{\mathrm{CO}}\left(1678 \mathrm{~cm}^{-1}\right.$ instead of $1699 \mathrm{~cm}^{-1}$ ) and, most conspicuously, in the existence of a ring stretching mode at $1471 \mathrm{~cm}^{-1}$ which is not seen here (while on the other hand the bands observed here at 1423 and $1370 \mathrm{~cm}^{-1}$ are not present for DKP).

We can go further in the characterization of adsorbed glycine, thanks to the high sensitivity of the CO stretch to the state of hydrogen bonding. From the data obtained for the conformers of free glycine, and for glycine:water complexes, ${ }^{15}$ we can estimate that the calculated frequencies have an accuracy of $\pm 20 \mathrm{~cm}^{-1}$. Therefore, the experimentally observed frequency of $1699 \mathrm{~cm}^{-1}$ is definitely incompatible with some models, namely those that are chiefly bonded through the amine moiety. In fact, the CO stretch frequencies calculated for the least stable conformations lie in the $1785-1800 \mathrm{~cm}^{-1}$ 
range, and thus can be excluded for energetic AND spectroscopic arguments. Conversely, the experimental value of $1699 \mathrm{~cm}^{-1}$ is close to that predicted for forms II-b, II-V-1 II-G, which are the most stable configurations with two silanols, and for form I-a, the most stable configuration with one silanol. All of these forms are H-bonded through the carboxyl moiety (acting both as an H-bond acceptor and an H-bond donor). The agreement is not so good for the configurations with three silanols $\left(1731-1738 \mathrm{~cm}^{-1}\right.$ calculated as compared to $1699 \mathrm{~cm}^{-1}$ experimental), although this could be due to an increase in the anharmonic factor when the number of H-bonds increases.

The data for the other vibrational modes of glycine seem to corroborate these findings. Thus, quite low $\delta \mathrm{HNH} / \mathrm{vCO}$ intensity ratioes are calculated $(=0.1)$ and the $\mathrm{HNH}$ bending frequencies are predicted in the $1615-1650 \mathrm{~cm}^{-1}$ range, in agreement with the experimental spectrum (and likely overlapping with $\mathrm{HOH}$ bending of adsorbed $\mathrm{H}_{2} \mathrm{O}$. Finally, for the $\mathrm{HCH}$ and $\mathrm{CCH}$ bending vibrations, a good agreement between experimental (1423 and $1371 \mathrm{~cm}^{-1}$ ) and calculated frequencies is obtained for forms Ib (1426 and $1379 \mathrm{~cm}^{-1}$ ), and to a lesser extent IIb (1450 and $\left.1392 \mathrm{~cm}^{-1}\right)$ and IIIa (1408 and $\left.1376 \mathrm{~cm}^{-1}\right)$.

It is encouraging that the theoretical adsorbed forms most in line with vibrational spectroscopy data are also calculated to be particularly stable energetically: form II-b (respectively II-V-1) is the most stable among the structures where glycine interacts with two free silanols, (respectively two vicinal silanols) and form I-a is the most stable structure for interaction with a single silanol.

DISCUSSION The most likely candidate structures for adsorbed glycine have a common feature: cooperative H-bonding between the carboxylic acid moiety and the silanol group. This kind of bonding is chemically reasonable, being rather similar to that commonly found for carboxylic acid dimers. ${ }^{32}$ In the latter case, the dissociation energy of the H-bonded dimer is -55 to $-60 \mathrm{~kJ} \mathrm{~mol}^{-1}{ }^{33}$, in the same range as the dissociation energies for adsorbed glycine complexes found in our work (Table I). Furthermore, a strong bathochromic shift of the $v_{\mathrm{CO}}$ vibration has been predicted and observed for the cyclic dimer, in line with the results discussed above for glycine on silica. It should be noted that Basyuk ${ }^{31,34}$ had 
hypothetically proposed similar structures for amino acids on silica, in addition to the "surface ester" model.

It is interesting to compare our results with those of ref 15. Among the considered 1:1 glycine:water complexes, the most stable has a conformation close to our Ia. configuration. This conformation is more stable by $15-20 \mathrm{~kJ} / \mathrm{mol}$ than the other ones, a trend also found in our configurations with one silanol (note that the calculation level is the same, B3LYP/6-31++G**). And, again, the conformations with binding through the $\mathrm{NH}_{2}$ moiety only are the less stable ones. The trend is conserved with the 1:2 Glycine:water complexes : their most stable structure is very similar to our IIb one. Differences between water and $\mathrm{SiOH}$ are visible only in the 1:3 complexes, where in the most stable complex shown by Ramaekers, the water molecules are not H-bonded to each other, whereas we have systematically observed that the structure with $3 \mathrm{SiOH}$ is stabilized by forming a hydrogen bond between two $\mathrm{SiOH}$. As regards the IR spectra, the Gly : Water complexes has a $v_{\mathrm{CO}}$ in the $1740-1720 \mathrm{~cm}^{-1}$ range, a value slightly superior to the $1699 \mathrm{~cm}^{-1}$ recorded for glycine on silica. In general, for the same structures, our calculated value of $v_{\mathrm{CO}}$ is lower than that found for the Gly/Water complexes (1723 for Ia against 1728 for 1:1 glycine/water complexes; 1701 for IIb against 1728 for $1: 2$ glycine/water complexes).

Coming back to the adsorbed forms, the formation of an additional CASB-type bond provides additional stabilization when it is not sterically hindered, but the cooperative $\mathrm{H}$-bonding of the $\mathrm{COOH}$ group remains present. Conversely, configurations in which glycine would be bound chiefly through its basic amine group are not favored, a conclusion that was not obvious beforehand.

We have mentioned in the results section that the « surface ester » model (三Si-O-(CO)-R) did not seem to fit with our experimental data. In order to further investigate this model, we have performed additional calculations on a glycine/silanol ester. They indicated that such a form would vibrate at 1757 $\mathrm{cm}^{-1}$ (CO stretch) and $1623 \mathrm{~cm}^{-1}$ (HNH bend). Those values, while close to those experimentally observed by Basyuk, ${ }^{30}$ were significantly different from those obtained for our systems, confirming that glycine may behave differently from other amino acids. We cannot exclude at this point that surface 
ester formation may be activated at higher temperatures, along $\mathrm{SiOH}+\mathrm{HOOC}-\mathrm{CH}_{2}-\mathrm{NH}_{2}---->\mathrm{SiOOC}-$ $\mathrm{CH}_{2}-\mathrm{NH}_{2}+\mathrm{H}_{2} \mathrm{O}$.

Another hypothesis that has been proposed previously is the formation of a direct Si-N bond, forming a pentacoordinated $\mathrm{Si}^{35}$ Additional calculations have shown that the formation of such a compound is very unfavorable thermodynamically (endothermic by around $200 \mathrm{~kJ} / \mathrm{mol}$ ). Finally, although it is well-known that many amino acids easily dimerise on the surface of silica to yield substituted diketopiperazines, ${ }^{36}$ this does not happen in our conditions, although it is quite likely that further thermal activation could promote dimerisation.

In summary, it is likely that glycine is bound to the surface, not through the formation of covalent bonds, but by hydrogen bonding according to one of the models proposed above. Silica could be said to act as a "solid solvent" for glycine, but it would be a quite different solvent from water, since it does not force glycine to change to the zwitterionic form.

If we accept the above models, we may wonder what kind of groups must be present on the silica surface to build a specific adsorption site for neutral glycine. In fact, the minimum requirement is that the site must be able to act both as an H-acceptor and as an H-donor in order to provide cooperative stabilization of the H-bonded molecule. This requirement may already be satisfied by one silanol, but the presence of two silanols does provide additional stabilization by separating the H-donor from the Hacceptor center.

In summary, the surface must present (at least) two functionally different groups in close vicinity to interact optimally with the adsorbing molecule. This is a case of « interactional complementarity », a phenomenon well-known in supramolecular chemistry, which has also been evidenced recently in the adsorption of nickel complexes on silica surfaces. ${ }^{36}$

CONCLUSION The adsorption of neutral glycine on silica was studied both theoretically and experimentally. Theoretical calculations suggest that glycine interacts preferentially via its $\mathrm{COOH}$ end with one or more SiOH groups, with the formation of one H-acceptor and one H-donor hydrogen bond 
with the silanols. Binding through the $\mathrm{NH}_{2}$ moiety can occur only in addition, once two bonds with $\mathrm{COOH}$ are formed. From the energetic criterion alone, the adsorption on clusters of three silanols should be favored compared to adsorption on one isolated and two adjacent silanols. However, the modifications of the energy of interaction due to the constraints induced by the surface cannot be evaluated with our method.

The comparison between the calculated and experimental vibrational frequencies confirms that glycine is bound through its $\mathrm{COOH}$ end with silanols; the calculated frequencies for the different functional groups of glycine $\left(\mathrm{CH}_{2}, \mathrm{NH}_{2}, \mathrm{COOH}\right)$ correspond best with glycine adsorbed on two vicinal, adjacent silanols.

These first results constitute a basis for future investigations of the glycine/silica system with more realistic models of the silica surface (i. e. larger clusters), including solvation effects.

AKNOWLEDGEMENTS We thank the French IDRIS center for attribution of computational time.

${ }^{1}$ Lofgren, P.; Krozer, A.; Lausmaa, J.; Kasemo, B. Surf. Sci., 1997, 370(2-3), 277.

${ }^{2}$ Barlow S. M.; Kitching K. J.; Haq S.; Richardson N. V. Surf. Sci., 1998, 401(3), 322.

${ }^{3}$ Munsch S.; Hartmann M.; Ernst S.; Chem. Commun., 2001, 19, 1978.

${ }^{4}$ Jones F. H. Surf. Sci. Rep., 2001, 42, 79.

${ }^{5}$ Bujdak J.; Rode B. M. J. Mol. Evol., 1997, 45(5), 457.

${ }^{6}$ Costa D.; Martra G.; Che M.; Manceron L.; Kermarec M. J. Am. Chem. Soc., 2002, 124(24), 7210. 
${ }^{7}$ Martra G.; Coluccia S.; Che M.; Manceron L.; Kermarec M., Costa D. J. Phys. Chem. B, 2003, 107(25), 6096.

${ }^{8}$ Meng M.; Stievano L.; Lambert J. F. Langmuir, 2004, 20(3), 914.

${ }^{9}$ Basiuk V. A. Surfactant Sci. Ser., 2003, 110, 45.

${ }^{10}$ Iler R. K. The Chemistry of Silica, 1979, Wiley-Interscience, New York.

${ }^{11}$ Stepanian S. G.; Reva I. D.; Radchenko E. D. ; Rosado M. T. S.; Duarte M.L.T.S.; Fausto R.; Adamowicz L.; J. Phys. Chem. A, 1998, 102(6), 1041.

12 Frisch M. J.; Trucks G. W.; Schlegel H. B.; Scuseria G. E.; Robb M. A.; Cheeseman J. R.; Zarkrewski V. G.; Montgomery Jr. J. A.; Stratmann R. E.; Burant J. C.; Dapprich S.; Millam J. M.; Daniels A. D.; Kudin K. N.; Strain M. C.; Farkas O.; Tomasi J.; Barone V.; Cossi M.; Cammi R.; Mennucci B.; Pomelli C.; Adamo C; Clifford S.; Ochterski W.; Petersson G. A.; Ayala P. Y.; Cui Q.; Morokuma K.; Salvador P.; Dannenberg J. J.; Malick D. K.; Rabuck A. D.; Raghavachari K.; Foresman J. B.; Cioslowski J.; Ortiz J. V.; Baboul A. G.; Stefanov B.B.; Liu G.; Liashenko A.; Piskorz P.; Komaromi I.; Gomperts R.; Martin R. L.; Fox D. J.; Keith T.; Al-Laham M. A.; Peng C. Y.; Nanayakkara A.; Challacombe M.; Gill P. M. W.; Johnson B.; Chen W.; Wong M. W.; Andres J. L.; Gonzalez C.; Head-Gordon M.; Replogle E. S. and Pople J. A. 2001, Gaussian, Inc., Pittsburgh PA.

${ }^{13}$ Noguera M.; Rodriguez-Santiago L.; Sodupe M.; Bertran J. Theochem, 2001, 537 , 307.

${ }^{14}$ Ramaekers, R ; Pajak, J. ; Lambie, B. ; Maes, G. J. Chem. Phys. 2004, 120(9), 4182.

${ }^{15}$ Vigné-Maeder F.; Sautet P., J. Phys. Chem. B, 1997, 101, 8197.

${ }^{16}$ Deak, P.; Solyom, A. Periodica Polytechnica, Chemical Engineering, 1990, 34, 121-6.

17 Civalleri B; Casassa S.; Garrone E.; Pisani C.; Ugliengo P. J. Phys. Chem. B, 1999, 103, 2165. 
${ }^{18}$ Civalleri B; Garrone E.; Ugliengo P. J. Phys. Chem. B, 1998, 102, 2373.

19 Garrone E.; Ugliengo P.; Ferrari A. M. Trends Phys. Chem., 1992, 3, 327.

${ }^{20}$ Masini; P.; Bernasconi; M. J. Phys.: Condens. Matter., 2002, 14, 4133.

${ }^{21}$ Civalleri B.; Garrone E.; Ugliengo P. Chem. Phys. Lett., 1998, 294, 103.

${ }^{22}$ Ferrari A. M.; Ugliengo P.; Garrone E., J. Phys. Chem., 1993, 97, 2671.

${ }^{23}$ Civalleri B.; Garrone E.; Ugliengo P., Langmuir, 1999, 15, 5829

${ }^{24}$ Civalleri B.; Casassa S.; Garrone E.; Pisani C.; Ugliengo P., J. Phys. Chem. B, 1999, 103, 2165.

${ }^{25}$ Wang, W.; Pu, X.; Zheng, W.; Wong, N.-B.; Tian; A. Theochem , 2003, 626 127-132.

${ }^{26}$ (a) Cooper; A. R.. In Proceedings of Conference on Boron in Glass and Glass Ceramics, Alfred University ; Pye, L. D., Frechette, V. D., Kreidl, N. J., Eds. ; Plenum Press : New York, 1978 ; p 167.

(b) Gladden, L. F.; Vignaux, M.; P. Chiaranussati, P.; Griffiths, R. W.; Jackson, S. D.; Jones, J. R.; Sharratt, A. P.; Robertson, F. J.; Webb, G.; Chieux, P.; Hannon, A. C., J. Non-Cryst. Solids, 1992, 47-59

${ }^{27}$ Nedelec J. M.; Hench, L. L. J. Non-Cryst. Sol., 1999, 255, 163.

28 Bell, J. R.; Dean, P. Philos. Mag., 1972, 25, 1381

29 Burneau, A.; Gallas, J-P. in The surface properties of silica, A. Legrand ed., J. Wiley, Chichester, 1998, pp.147-234.

30 Morrow, B.A. Stud. Surf. Sci. Catal., 1990, 67A, 161.

${ }^{31}$ Basyuk, V. A.; Russ. J. Theor. Exp. Chem., 1990, 26, 89

${ }^{32}$ Florio, G. M. ; Zwier, T. ; Myshakin, E.M. ; Jordan K. D. ; Silbert E. L. J. Chem. Phys. 2003, 118, 1735 
${ }^{33}$ Emmeluth, C. ; Suhm, M. A., Phys. Chem Chem Phys, 2003, 5, 3094

${ }^{34}$ Gun'ko, V. M.; Basyuk, V. A.; Chernyavskaya, T. V.; Chuiko, A. A. Ukr. Khim. Z.,1990, 56, 571

${ }^{35}$ West, J. K.; Hench, L. L. J. Biomed. Mat Res. 1994, 28(5), 625-33.

${ }^{36}$ Basiuk, V.A.; Gromovoy, T. Yu.; Chuiko, A.A.; Soloshonok, V.A.; Kukhar, V.P. Synthesis, 1992, 5, 449 .

${ }^{37}$ Boujday S.; Lambert J. F.; Che, M. J. Phys. Chem. B, 2003, 107, 651-654 